\title{
Chist congenital de coledoc la un sugar - caz clinic şi review de literatură
}

\author{
Smaranda Diaconescu ${ }^{1,2}$, Silvia Strat ${ }^{2}$, Andreea Nichita ${ }^{2}$, Gabriela Păduraru ${ }^{1,2}$, \\ Gabriela Ghiga ${ }^{1}$, Oana Maria Roşu², Ana Maria Scurtu², Cristina Alexa², \\ Petru Plămadeală², Eduard Vasile Roşu², Lorenza Donea ${ }^{2}$ \\ ${ }^{1}$ Universitatea de Medicină şi Farmacie „Grigore T. Popa“, Iaşi, România \\ ${ }^{2}$ Secţia Clinică Gastroenterologie Pediatrică, \\ Spitalul Clinic de Urgenţă pentru Copii „Sf. Maria“, Iaşi, România
}

\begin{abstract}
REZUMAT
Chistul congenital de coledoc este mai frecvent diagnosticat la copiii până la 10 ani, afectând preponderent persoanele de sex feminin. Prezentăm un caz de chist coledocian la un sugar de sex masculin în vârstă de 7 luni, care a debutat brusc cu icter sclerotegumentar şi inapetenţă. Ecografia abdominală a evidenţiat o formaţiune transsonică, hiperreflectogenă, cu localizare pe topografia coledocului, căi biliare intrahepatice dilatate, iar examenele de laborator au decelat un sindrom sever de citoliză hepatică şi colestază. Diagnosticul a fost confirmat cu ajutorul IRM colangiopancreatic efectuat în urgenţă şi a impus intervenţia chirurgicală. Diagnosticul diferenţial al sindroamelor de colestază trebuie să excludă şi chistul coledocian, indiferent de vârsta pacientului, din cauza complicaţiilor şi riscului de malignizare.
\end{abstract}

Cuvinte cheie: chist coledocian, icter, colestază, sugar

\section{Listă de abrevieri}

CCC: Chist coledocian congenital

CBIH: Căi biliare intrahepatice

AP/T/CC: Antero-posterior/transvers/cranio-caudal

APTT: Timp de tromboplastină parţial activată

BD: Bilirubina directă

BI: Bilirubina indirectă

BT: Bilirubina totală

CHEM: Concentraţia hemoglobinei eritrocitare medii

\author{
ERCP: Colangiografie endoscopică retrogradă \\ FA: Fosfatază alcalină \\ GGT: Gama-glutamil transpeptidază \\ PT: Timp de protrombină \\ TGO: Aspartataminotransferază \\ TGP: Alanin-aminotransferază \\ VEM: Volum eritrocitar mediu
}

\section{INTRODUCERE}

Chistul congenital coledocian (CCC) este o malformaţie transmisă autozomal recesiv, ce exprimă un defect genetic de structurare a arborelui biliar şi face parte din categoria afecţiunilor care prin stază biliară pot determina ciroza biliară şi hipertensiune portală (1).

Patologia este rar întâlnită, până în 1984, în literatura medicală internaţională raportându-se doar 1.532 de cazuri, iar până în 2000, aproximativ 2.430. Accentul este plasat din ce în ce mai mult pe importanţa ecografiei, iar pentru diagnosticul pozitiv pe confirmarea prin colangiografie IRM (2).
Chistul congenital de coledoc poate fi clinic silenţios (descoperit incidental, în timpul efectuării unei ecografii abdominale de rutină sau în timpul unei intervenţii chirurgicale cu viză pe etajul abdominal superior) sau poate fi exprimat clinic prin triada clasică descrisă de Sénéque şi Tailhefer (durere în hipocondrul drept, icter sclero-tegumentar, formaţiune tumorală palpabilă în hipocondrul drept), dar şi direct, prin complicaţii precum litiaza biliară, angiocolita, pancreatita acută (ce predomină în tipul III şi în tipul IV A Todani), sau fenomene de hipertensiune portală (3). 
Prezentăm un caz de chist coledocian la un sugar de 7 luni la care diagnosticul precoce a permis o intervenţie chirurgicală promptă.

\section{CAZ CLINIC}

Pacientul, în vârstă de 7 luni, de sex masculin, fără antecedente personale patologice semnificative, se prezintă în clinica de Gastroenterologie Pediatrică prin transfer de la un spital din teritoriu, unde a efectuat o ecografie abdominală, în contextul icterului sclerotegumentar apărut de aproximativ 4 zile, cu ajutorul căreia s-a decelat un chist la nivelul segmentului V hepatic.

La internare, sugarul prezintă icter sclerotegumentar, facies dismorfic, fibrocondroame preauriculare şi peribucale, cardio-pulmonar stetacustic normal, abdomen uşor meteorizat, depresibil, mobil cu mişcările respiratorii, absenţa formaţiunilor tumorale palpabile, scaune acolice, diureza prezentă, urini hipercrome, absenţa semnelor de iritaţie meningeană.

Paraclinic, prezintă eozinofilie, anemie hipocromă normocitară, sindrom inflamator prezent, sindrom de hepatocitoliză (transaminaze $5 \times \mathrm{VN}$ ), hiperamoniemie $(2 x V N)$ hiperbilirubinemie $(\mathrm{BD}=6,95 \mathrm{mg} / \mathrm{dl}, \mathrm{BT}=8,77 \mathrm{md} / \mathrm{dl})$, hipercolesterolemie, hipertrigliceridemie, GGT $=1.869 \mathrm{U} / 1$, $\mathrm{FA}=1.695 \mathrm{U} / 1, \mathrm{PT}$ uşor prelungit. Electroforeza proteinelor relevă fracţiunea alfa 1 globulina crescută şi gamaglobulinele scăzute.

TABELUL 1. Tabloul paraclinic

\begin{tabular}{|l|c|c|}
\hline Parametrul & Valoarea înregistrată & Intervalul de referință \\
\hline Eozinofile & $0,42 * 10^{5} \mu \mathrm{l}$ & $0-0,3 * 10^{5} \mu \mathrm{l}$ \\
\hline Eozinofile \% & $5,5 \%$ & $0-5 \%$ \\
\hline Hemoglobină & $10,5 \mathrm{~g} / \mathrm{dl}$ & $11,4-14 \mathrm{~g} / \mathrm{dl}$ \\
\hline Hematocrit & $30,8 \%$ & $33-41 \%$ \\
\hline VEM & $70,8 \mathrm{fL}$ & $70-85 \mathrm{fL}$ \\
\hline CHEM & $24,1 \mathrm{pg}$ & $25-30 \mathrm{pg}$ \\
\hline APTT & $22,3 \mathrm{secunde}$ & $23-34 \mathrm{secunde}$ \\
\hline PT & $17,4 \mathrm{secunde}$ & $13-17 \mathrm{secunde}$ \\
\hline TGO & $216 \mathrm{U} / \mathrm{l}$ & $5-35 \mathrm{U} / \mathrm{l}$ \\
\hline TGP & $210 \mathrm{U} / \mathrm{l}$ & $5-38 \mathrm{U} / \mathrm{l}$ \\
\hline GGT & $1.869 \mathrm{U} / \mathrm{l}$ & $7-55 \mathrm{U} / \mathrm{l}$ \\
\hline FA & $1.695 \mathrm{U} / \mathrm{l}$ & $40-600 \mathrm{U} / \mathrm{l}$ \\
\hline BT & $8,77 \mathrm{mg} / \mathrm{dl}$ & $0,25-1 \mathrm{mg} / \mathrm{dl}$ \\
\hline BD & $6,95 \mathrm{mg} / \mathrm{dl}$ & $0-0,25 \mathrm{mg} / \mathrm{dl}$ \\
\hline BI & $1,82 \mathrm{mg} / \mathrm{dl}$ & \\
\hline Colesterol total & $355 \mathrm{mg} / \mathrm{dl}$ & $100-200 \mathrm{mg} / \mathrm{dl}$ \\
\hline Trigliceride & $256 \mathrm{mg} / \mathrm{dl}$ & $40-150 \mathrm{mg} / \mathrm{dl}$ \\
\hline Proteine totale & $57,94 \mathrm{~g} / \mathrm{l}$ & $46-68 \mathrm{~g} / \mathrm{l}$ \\
\hline Alfa1 & $5,3 \%$ & $1,4-4 \%$ \\
\hline Gama & $4,17 \mathrm{~g} / \mathrm{l}$ & $5,84-13,2 \mathrm{~g} / \mathrm{l}$ \\
\hline Creatinină & $0,91 \mathrm{mg} / \mathrm{dl}$ & $0,1-0,5 \mathrm{mg} / \mathrm{dl}$ \\
\hline & & \\
\hline
\end{tabular}

\begin{tabular}{|l|c|c|}
\hline Parametrul & Valoarea înregistrată & Intervalul de referință \\
\hline Uree & $6 \mathrm{mg} / \mathrm{dl}$ & $10-40 \mathrm{mg} / \mathrm{dl}$ \\
\hline Amoniac & $81,24 \mu \mathrm{mol} / \mathrm{l}$ & $0-47 \mu \mathrm{mol} / \mathrm{l}$ \\
\hline CRP & $15,9 \mathrm{mg} / \mathrm{dl}$ & $0-5 \mathrm{mg} / \mathrm{l}$ \\
\hline IgM & $27 \mathrm{mg} / \mathrm{dl}$ & $36-104 \mathrm{mg} / \mathrm{dl}$ \\
\hline
\end{tabular}

S-au recoltat Ac anti citomegalovirus tip IgG, Ac anti Toxoplasma gondii, Ac heterofili, Ac anti virus Epstein Barr tip IgG, Ag HBs, Ac anti VHC, Ac anti HAV Ig $\mathrm{M}-$ cu rezultate negative.

Ecografia abdominală evidenţiază ficat cu dimensiui normale, structură omogenă, reflectivitate normală; colecist alitiazic; formaţiune transsonică cu depozit decliv hiperreflectogen, având dimensiuni de 5,33/3,31 cm cu localizare pe topografia coledocului; vena portă normală; căile biliare intrahepatice $(\mathrm{CBIH})$ dilatatate; lamă de lichid cu grosimea de $0,9 \mathrm{~cm}$ subhepatic; rinichi normali ecografic; pancreas nevizualizabil; splină cu structură omogenă. Vezica urinară în semirepleţie, cu conţinut transonic (Fig. 1 A, B, C).
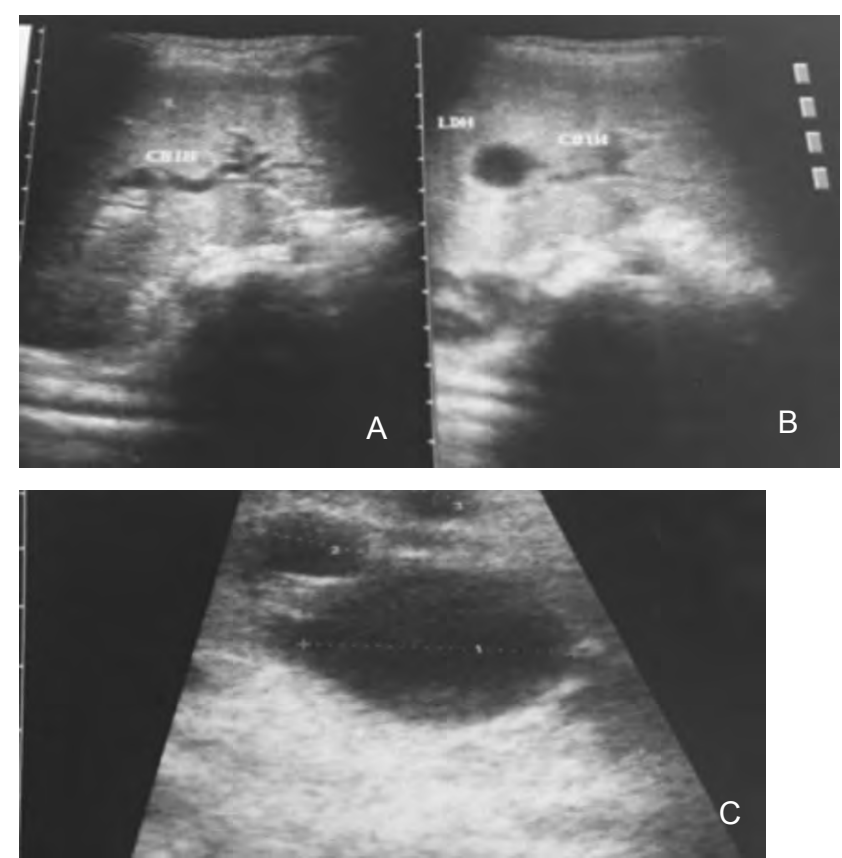

FIGURA 1. A, B şi C. Aspecte ecografice

S-a iniţiat tratament cu arginină, acid ursodeoxicolic şi protectoare hepatice.

Colangiopancreatografia IRM efectuată în urgenţă descrie o formaţiune expansivă ovalară, cu perete subţire, conţinut cu semnal de tip biliar, fără captarea substanţei de contrast, localizată în hilul hepatic, având dimensiuni de 36/35/60 mm (AP/T/ CC) - obs. coledococel (Fig. 2).

Formaţiunea are originea la nivelul bifurcaţiei canalului biliar principal, exercită efect de masă asupra colecistului, capului pancreatic şi potcoavei 
duodenale. Duct cistic dilatat în porţiunea distală până la $9 \mathrm{~mm}$. CBIH dilatate până la $4,3 \mathrm{~mm}$ la nivelul ramului principal stâng.
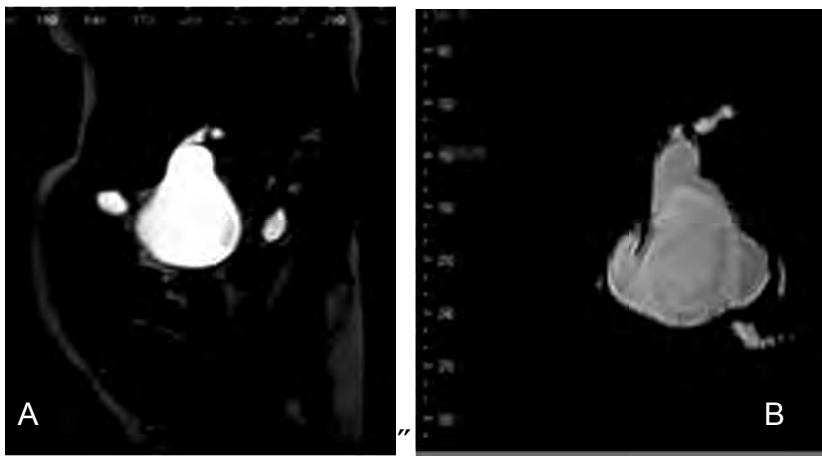

FIGURA 2. A şi B - Aspecte colangiopancreato IRM

Pacientul a fost transferat în secţia chirurgie pediatrică în vederea realizării intervenţiei chirurgicale. S-a practicat incizie Kocher, ablaţia chistului, colecistectomie, derivatie biliodigestivă, anastomoză a la Roux latero-terminală şi biopsie hepatică (Fig. 3. A şi B).
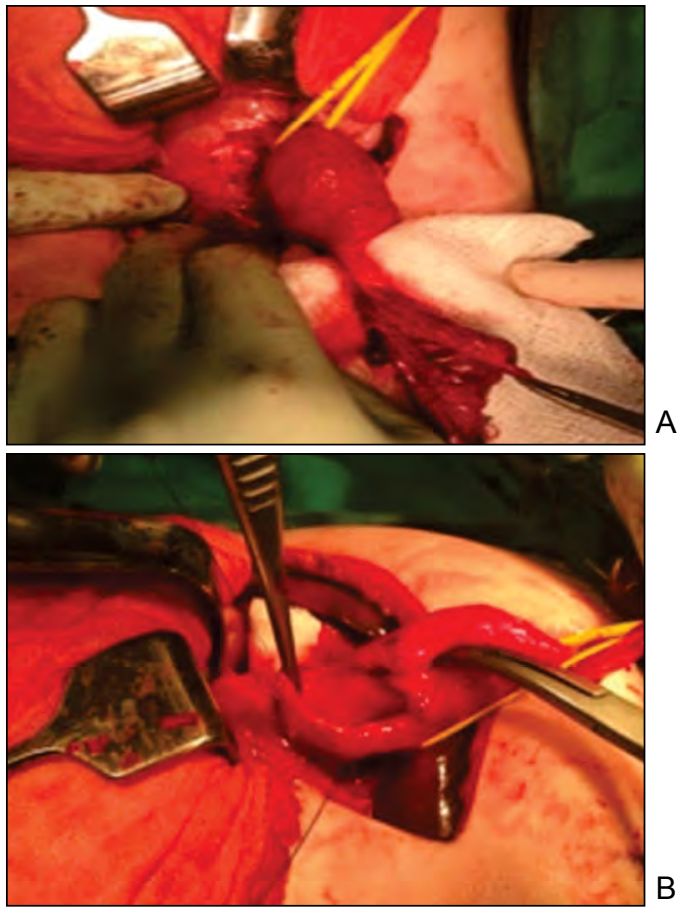

FIGURA 3. A şi B - Aspecte intraoperatorii

Postoperator, s-a instituit transfuzie de masă eritrocitară, ulterior albumină, antibioticoterapie în dublă asociere (metronidazol şi piperacilină/tazobactam), pantoprazol şi simptomatice cu normalizarea valorilor transaminazelor, menţine uşoară hiperbilirubinemie pe baza bilirubinei directe, sindromul inflamator se remite, ceilalţi parametri biologici sunt normalizaţi.

Rezultatul examenului anatomo-patologic a confirmat prezenţa chistului de coledoc, iar biopsia hepatică a relevat un ficat de colestază şi inflamaţie pericentrolobulară.

Evoluţia postoperatorie a fost favorabilă, fără complicaţii, sugarul fiind externat în a 11-a zi după intervenţie. Reevaluarea la o lună relevă normalizarea tabloului clinic şi paraclinic şi absenţa imaginilor patologice ecografice.

\section{DISCUȚII}

Există mai multe teorii etiopatogenice, printre care amintim teoria embriologică (Yotsyanagi, 1936- defect de embriogeneză în săptămânile 8-12 de gestaţie), teoria ageneziei nervoase intramurale, teoria atreziei parţiale a căilor biliare, teoria joncţiunii bilio-pancreatice înalte (un canal comun mai lung permite refluxul secreţiei pancreatice, cu distrucţia enzimatică a mucoasei biliare favorizând dilatarea), asociată cu un risc crescut de malignizare, şi teoria obstrucţiei distale a căii biliare principale printr-un nodul fibros, afecţiune valvulară sau cudură (1).

Într-un studiu s-a raportat un lot de 14 copii cu chist de coledoc cu vârsta medie de 5,2 ani (între 1 şi 15 ani) (2). Autori români raportează un lot în care vârsta pacienţilor a fost cuprinsă între 9 luni şi 10 ani, cu o medie de 2 ani şi 4 luni (1). În cazul nostru, sugarul a fost diagnosticat la vârta de 7 luni, relativ precoce comparând cu vârsta medie de diagnostic raportată.

În loturile studiate, repartiţia pe sexe a fost în favoarea sexului feminin, acesta reprezentând procente de $100 \%, 71,42 \%$, Poddar descriind incidenţe egale între sexe $(1,2,4)$.

Autorii raportează un lot de 14 pacienţi în care triada clinică clasică (icter, durere abdominală și formaţiune tumorală palpabilă) a fost întâlnită în doar două cazuri, în celelalte predominând icterul sclero-tegumentar şi sindromul dureros abdominal (2). În cazul nostru, simptomatologia a constat în prezenţa icterului, scaunelor acolice şi urinilor hipercrome, durerea abdominală fiind dificil de apreciat la sugar.

ERCP este metoda de elecţie în diagnosticarea şi managementul minimum invaziv al $\mathrm{CC}$ şi al litiazei coledociene şi intrachistice asociate, însă are utilitate limitată la copilul mic. Astfel, ecografia rămâne metoda de screening de elecţie pentru malformaţiile arborelui biliar, pentru confirmare de primă intenţie fiind colangiografia (IRM sau intraoperatorie) (5).

Unii autori raportează faptul ca diametrul caii biliare principale ar trebui să fie sub 1,6 mm la sugar şi sub $3 \mathrm{~mm}$ la copil, în timp ce alţii susţ̧in că 
evidenţierea ecografică a ductelor biliare intrahepatice sau a căii biliare principale cu diametrul mai mare de $2 \mathrm{~mm}$ la sugari, mai mare de $4 \mathrm{~mm}$ la copil şi mai mare de $7 \mathrm{~mm}$ după adolescenţă reprezintă aspecte patologice (6). În cazul de față s-a remarcat o dilataţie a ductelor biliare intrahepatice de până la $4,3 \mathrm{~mm}$, aspecte ce se încadrează în afara fiziologicului indiferent de criteriile aplicate.

Lee descrie în lotul raportat media dimensiunilor CCC de 21,4+/-12,1 mm (5). În cazul nostru, dimensiunile CCC au fost de 36/35/60 mm, peste media descrisă.

În ceea ce priveşte tratamentul, acesta a fost chirurgical în proporţie de $100 \%$, în $57,1 \%$ dintre cazuri practicându-se anastomoză bilio-jejunală în Y à la Roux, iar în 42,9\% anastomoză bilio-duodenală, diferenţa atât în rata complicaţiilor, cât şi a perioadei de spitalizare dintre cele două subloturi raportate de Hector Silva-Baez neefind statistic semnificativă $(\mathrm{P}=0,71 \%)(2)$.

În lotul mai sus menţionat, excizia chistului a fost urmată de refacerea circuitului biliar prin anastomoză bilio-jejunală în Y à la Roux, în 6 cazuri, iar în 2 cazuri a fost practicată anastomoză hepatico-duodenală. Evoluţia raportată a fost favorabilă, observându-se o dezvoltare antropometrică normală (2).

În ceea ce privește tratamentul, autorii străini consideră că excizia chistului şi anastomoza biliojejunală cu ansă în ,YY" à la Roux reprezintă procedura de elecţie oferind cele mai bune rezultate, procedeu aplicat şi pacientului nostru, cu evoluţie postoperatorie fără complicaţii. În trecut se utiliza drenajul intern al chistului (chistoduodenoanastomoza) care însă genera o rată înaltă de morbiditate prin prisma posibilelor complicaţii (stenoză, stază biliară, litiază biliară, colangită) dar şi prin riscul ridicat de apariţie al carcinomului de cale biliară (7).

Excizia chistului nu este întotdeauna uşoară, la copilul mic disecţia şi separarea chistului de artera

\section{BIBLIOGRAFIE}

1. Aprodu G, lonescu S, Mihaială D, Botez C. Chistul congenital de coledoc - modalităţi de diagnostic şi tratament. Educaţie medicală continuă - Chirurgie generală. 2005

2. Hector Silva-Baez et al. Treatment of choledochal cyst in a pediatric population. A single institution experience of 15-years. Case series. Ann Med Surg (Lond). 2016 Feb; 5: 81-85.

3. Soares KC, Arnaoutakis DJ, Kamel I, Rastegar N, Anders R, Maithel S. Choledochal cysts: Presentation, clinical differentiation, and management. J. Am. Coll. Surg. 2014;219(6):1167-1180.

4. Poddar U, Vijayaraghavan P1, Lal R, Sikora SS, Yachha SK. Experience with choledochal cysts in infants. Pediatr Surg Int. 2006 Oct;22(10):803-7. hepatică şi vena portă fiind de obicei facilă, însă dificultăţile apar atunci când există aderenţe şi morfologia locală este modificată. Cura chirurgicală laparoscopică are indicaţie în tratamentul CC în special pentru tipul I Todani, aceasta fiind menţionată în literatură (8).

Poddar relatează o predominanţă a tipurilor I si IV A Todani în lotul de pacienţi studiat. De asemenea, în acest lot s-au înregistrat 6 cazuri de ciroză biliară secundară, 2 cazuri de atrezie de căi biliare extrahepatice şi un caz de fibroza hepatică congenitală (4). În cazul de faţă, corelarea datelor imagistice şi intraoperatorii trasează diagnosticul de chist congenital de coledoc tip I Todani, cel mai frecvent tip de CCC. Biopsia hepatică a indicat inflamaţie pericentrolobulară, subliniind astfel importanţa managementului precoce al CCC, înaintea instalării fibrozei hepatice.

\section{CONCLUZII}

Chistul congenital al căilor biliare este rar întâlnit în aria noastră geografică, dar trebuie să fie considerat în diagnosticul diferenţial al sindromului biliar cu evoluție recurentă la copil.

Simptomatologia variază, mai ales la sugari, unde triada clasică este aproape imposibil de evidenţiat. Suspiciunea clinică trebuie întotdeauna urmată de investigaţii imagistice, diagnosticul şi managementul precoce permitând evoluţii favorabile însoţite de complicaţii minime.

Intervenţiile radicale nu sunt întotdeauna posibile, din cauza dificultăţilor tehnice determinate de modificarea morfologiei locale, dar şi din cauza alterării stării pacienţilor. Astfel, intervenţia terapeutică trebuie adaptată fiecărui pacient în parte, bolnavii operaţi fiind monitorizaţi de-a lungul vieţii din cauza posibilităţii apariţiei unor complicaţii tardive (angiocolită, litiază, ciroză biliară, ruptura chistului, pancreatită acută, compresiune pe structurile învecinate, malignizare).

Conflict of interest: none declared Financial support: none declared

5. Ouaïssi M et al. Todani Type II Congenital Bile Duct Cyst: European Multicenter Study of the French Surgical Association and Literature Review. Ann Surg. 2015 Jul;262(1):130-8.

6. Hung-Chang Lee. Ultrasonography of Choledochal Cysts in Children. J Med Ultrasound. 2007:15:191-196.

7. Ragot $E$ et al. Pancreaticobiliary Maljunctions in European Patients with Bile Duct Cysts: Results of the Multicenter Study of the French Surgical Association (AFC). World J Surg. 2017 Feb;41(2):538-545.

8. Gadelhak N, Shehta A, Hamed H. Diagnosis and management of choledochal cyst: 20 years of single center experience. World J. Gastroenterol. 2014;20(22):7061-7066. 